\title{
Drugs or disease: evaluating salivary function in RA patients
}

\section{Sandra Regina TORRES(a) Carlos Henrique Silva PEDRAZAS(a) Marcos Paulo Veloso CORREIA(b) Mario Newton Leitão de AZEVEDO(b) Thaís ZAMPROGNO(a) Arley SILVA JUNIOR ${ }^{(a)}$ Lucio Souza GONÇALVES(c) José Angelo de Souza PAPI(b)}

(a) Universidade Federal do Rio de Janeiro - UFRJ, School of Dentistry and Oral Health Program, Clementino Fraga Filho University Hospital, Department of Oral Pathology and Oral Diagnostic, Rio de Janeiro, RJ, Brazil.

(b) Universidade Federal do Rio de Janeiro - UFRJ, Clementino Fraga Filho University Hospital, Department of Internal Medicine, Rio de Janeiro, RJ, Brazil.

(c) Universidade Estácio de Sá, Postgraduate Program in Dentistry, Rio de Janeiro, RJ, Brazil.

Declaration of Interests: The authors certify that they have no commercial or associative interest that represents a conflict of interest in connection with the manuscript.

\section{Corresponding Author:}

Sandra Regina Torres

E-mail: sandratorres@ufri.br

DOI: 10.1590/1807-3107BOR-2016.vol30.0106

Submitted: Nov 16, 2015

Accepted for publication: May 11, 2016

Last revision: Jul 19, 2016
Abstract: Oral complications of RA may include temporomandibular joint disorders, mucosa alterations and symptoms of dry mouth. The aim of this study was to evaluate the salivary gland function of subjects with rheumatoid arthritis (RA) comparing it to healthy controls. Subjects with other systemic conditions known to affect salivary functions were excluded. A questionnaire was applied for the evaluation of xerostomia. Resting and chewing-stimulated salivary flow rates (SFR) were obtained under standard conditions. There were 145 subjects included of the study (104 RA and 38 controls). About $66.7 \%$ of the RA subjects and $2.4 \%$ in control group presented xerostomia. The median resting SFR were $0.24 \mathrm{ml} / \mathrm{min}$ for RA subjects and $0.40 \mathrm{~mL} / \mathrm{min}$ for controls $(\mathrm{p}=0.04)$. The median stimulated SFR were $1.31 \mathrm{~mL} / \mathrm{min}$ for RA subjects and $1.52 \mathrm{ml} / \mathrm{min}$ for controls $(\mathrm{p}=0.33)$. No significant differences were found between resting and stimulated SFR of RA subjects not using xerogenic medications and controls. There was significantly higher number of subjects presenting hyposalivation in the RA group than among controls, even when subjects using xerogenic medications were eliminated from the analysis. In conclusion, hyposalivation and xerostomia were more frequent among RA subjects not using xerogenic medication than among controls, although there were no significant differences in the median SFR between groups.

Keywords: Saliva; Salivary Glands; Xerostomia; Arthritis, Rheumatoid.

\section{Introduction}

Rheumatoid Arthritis (RA) is the most common rheumatic disease. It is a chronic inflammatory autoimmune disease characterized by joint swelling and tenderness and destruction of synovial joints, leading to severe disability and premature mortality ${ }^{1}$. Oral complications of RA may include temporomandibular joint disorders ${ }^{2,3}$, mucosa alterations ${ }^{4}$ and complaints of dry mouth ${ }^{5}$. Some studies have evaluated the salivary flow rates (SFR) in RA subjects, not associated with secondary Sjögren's syndrome, but most of them do not distinguish patients with secondary autoimmune diseases $2,6,7,8,9,10,11$.

Extra-articular involvement may be observed in RA patients, including organs like the skin, eye, heart, lung, kidney, and the nervous and gastrointestinal system ${ }^{12}$. Salivary function may be affected in clinically diagnosed RA patients ${ }^{2,6,8,13}$. Extra-articular manifestations of RA are a result of vessel vasculitis, sometimes followed by necrosis of the vessel wall and artery occlusion, in most of the affected organs ${ }^{12}$. Minor salivary gland 
histology taken from lip biopsy of RA patients, varies from small lymphocytic infiltrates without lobular destruction to extensive round-cell infiltration with partial destruction of acinar tissue with or without fibrosis ${ }^{14}$. Sjögren's patients present focal lymphocytic sialoadenitis, sometimes with extensive sclerosis destroying the lobular architecture ${ }^{14,15}$. In patients with secondary Sjögren's syndrome, the autoimmune changes which affect salivary gland function appear due to progressing lymphocytic infiltration in salivary acini, which in turn leads to acinar atrophy and proliferation of connective tissue ${ }^{5}$. The mechanism by which the salivary glands are affected in patients with RA has not been described.

The prevalence of hyposalivation varies from $14.4 \%$ to $25.5 \%$ in the general population, and it has been reported as $17.4 \%$ in the patients with $\mathrm{RA}^{11,16,17}$. However, the reduced SFR in RA patients may be a consequence of the large amount of medications taken by these patients. The influence of xerogenic medications on the SFR of these subjects has rarely been studied?

When salivary functions are reduced there may be severe oral health consequences like xerostomia, changes in salivary composition, difficulty in mastication, dysphagia, dysphasia, dysgeusia/hypogeusia, oral microbiota alterations, and increased decay and periodontal disease susceptibility ${ }^{17,18}$. Notevery individual who presents reduced SFR reports xerostomia, and vice-versa ${ }^{19,20}$. Sialometry is a non-invasive, low-costing, quick and easy test for quantifying SFR. If sialometry is performed routinely in clinical practice, it may be used as a marker for systemic disease diagnosis and for special care in oral health.

The aim of this study was to evaluate the salivary gland function and the role of xerogenic drugs on the salivary function in subjects with RA. Our null hypothesis was that SFR of subjects with RA are similar to the SFR of healthy controls.

\section{Methodology}

\section{Study population}

This is a cross-sectional study in which the salivary function of RA subjects was compared to healthy controls. Patients with immunomediated/colagenous diseases were referred for oral evaluation at the
Stomatology Clinic of the Universidade Federal do Rio de Janeiro (UFRJ) School of Dentistry, from physicians of the Rheumatology and Collagenose Clinic of the Hospital Universitário Clementino Fraga Filho (HUCFF) of the same university, from March 2002 to June 2005.

A convenience sample with all subjects over 18 years of age with seropositive RA were selected for the study. Rheumatoid arthritis was diagnosed according to the American College of Rheumatology criteria $^{21}$ The RA subjects presenting other underlying conditions that potentially affect salivary flow rates (other immunomediated/colagenous disease, diabetes, human immunodeficiency virus infection, hepatitis $\mathrm{C}$, and with history of radiotherapy or chemotherapy) were excluded from the study.

Control group was composed by healthy subjects over 18 years of age, who attended the clinics at the UFRJ School of Dentistry. Controls in the same age range of RA subjects were invited to participate in the study. Subjects were excluded of control group if reported any health issue or if using medications.

The research was ethically conducted according to the Helsinki Declaration (World Medical Association). The study was approved by the institutional ethics committee, protocol number 015/03-CEP. Fully informed voluntary consent was obtained from each individual that participated in the study.

\section{Data collection}

The RA subjects' history and medications were taken from medical records. The medications included as disease-modifying antirheumatic drugs (DMARDs) were azathioprine, biologics, cyclophosphamide, cyclosporine, hydroxychloroquine, leflunomide, methotrexate, sulfasalazine, and tofacitinib ${ }^{22}$. Subjects were further analyzed in subgroups using or not xerogenic medications. The following drugs were considered xerogenic medications: anti-acid, anti-hypertensive, beta-blocker, diuretic, and psychotropic drugs. The medical history of controls was obtained through the interview of subjects.

Oral examination and sialometry were performed at the Stomatology Clinic, for every subject. A questionnaire was applied for the evaluation of xerostomia and associated symptoms ${ }^{15}$. 
Samples of resting and chewing-stimulated whole saliva were obtained under standard conditions. ${ }^{23}$ Saliva specimens were collected between 9 am and 11 am and no food, liquids, smoking, or hygienic habits were allowed for $120 \mathrm{~min}$ before the test section. For the resting SFR measurement, participants were asked to sit in a relaxed and upright position, and all produced saliva was periodically disposed into a disposable recipient, for a period of five minutes. For the stimulated sialometry, the participants were asked to chew preweighed $(1 \mathrm{~g})$ unflavored gum for 6 minutes. During the first minute they were instructed to swallow saliva as they chewed the gum, and then, they were asked to dispose the accumulated saliva, periodically, into a disposable container, for a period of five minutes. Saliva was then aspirated from the disposable cup with a graduated syringe and measured. Only the liquid component (not the foam) of saliva was measured. The SFR was determined as milliliters per minute.

The degree of salivary function was classified as normal (resting $\geq 0.3$; stimulated $\geq 1 \mathrm{~mL} / \mathrm{min}$ ); intermediate (resting $>0.1$ to $<0.3$; stimulated $>0.7$ to $<1.0 \mathrm{~mL} / \mathrm{min}$ ); and hyposalivation (resting $\leq 0.1$; stimulated $\leq 0.7 \mathrm{~mL} / \mathrm{min})^{11,13}$

\section{Statistical analysis}

Chi-square or Fisher's exact test were used to analyze differences in categorical data, and Mann-Whitney test for non-parametrical measured data. The $p$-value was set at 0.05 . The SPSS $\odot$ program, version 13.0 (SPSS Inc., IBM Company Headquarters, Chicago, Illinois, US), was used for storing and analyzing data.

\section{Results}

Twohundred and ten patients withimmunomediated/ colagenous disease were referred to the Stomatology Clinic during the study period. From these patients, 131 presented seropositive RA, but only 104 fulfilled the study criteria. Twenty seven RA patients were excluded for having one or more than these conditions: secondary Sjögren's syndrome ( $n=11)$, lupus erythematous $(n=9)$, diabetes $(n=7)$, hypothireoidism $(n=3)$, radioactive iodine therapy $(n=3)$, radiotherapy of head and neck $(n=3)$, stem cell transplant $(n=3)$, or other conditions like scleroderma, lipoproteinemia, hemochromatosis, cystic fibrosis, Parkinson's disease, or dehydratation.
Forty one subjects were included in the control group, after 63 exclusions for having underlying systemic conditions, or for taking drugs that might interfere in salivary function. The clinical and demographic data of the 145 studied subjects are summarized in Table 1.

Regarding the habits that could result in xerostomia, coffee drinking was the most prevalent habit in subjects from both groups of the study, and more RA subjects consumed coffee than subjects in control group $(p<0.01)$. But there were no differences in xerostomia and SFR of RA subjects who consumed coffee when compared with those who did not report the habit (data not shown). Forty six percent of the RA subjects and $68 \%$ of control subjects drank more than one litter of water a day. There were more subjects drinking less than half a litter of water in the RA group $(p=0.04)($ Table 1$)$.

More than half $(55.3 \%)$ of the subjects with RA reported at least one positive answer in the xerostomia related symptoms questionnaire, while none of the subjects in the control group had a positive answer to these questions. The majority of RA subjects reported intermittently xerostomia (66.7\%), and $44.1 \%$ of them reported symptoms of dry mouth for more than 6 months. The symptoms related to salivary function are shown in Table 2.

None of the subjects had a history of enlarged parotid gland, and one RA subject had a history of submandibular gland enlargement, which resolved with antibiotic. All controls presented normal saliva drainage of major salivary glands, but more than $10 \%$ of the RA subjects presented lack of saliva drainage in at least one of the major salivary glands (Table 3).

The median resting SFR were lower in RA subjects, but there were no differences in the median values of stimulated SFR between RA and controls (Table 3). Regarding the degree of salivary function, there were significantly more subjects with hyposalivation among RA subjects, than among controls, when defined by the results of resting sialometry (Table 3).

No significant differences were found when the resting and stimulated SFR of the 21 (20.2\%) RA subjects that presented no saliva drainage from at least one of the major salivary gland were compared with theSFR of the other RA subjects who presented normal saliva drainage from all major glands. The median resting SFR of these 
Drugs or disease: evaluating salivary function in RA patients

Table 1. Clinical and demographic characteristic of the 145 studied subjects.

\begin{tabular}{|c|c|c|c|}
\hline \multirow{2}{*}{ Demographic and clinical data } & Rheumatoid arthritis & Control group & \multirow{2}{*}{ p-value } \\
\hline & $\mathrm{n}=104(\%)$ & $\mathrm{n}=41(\%)$ & \\
\hline \multicolumn{4}{|l|}{ Age } \\
\hline Median & 53.0 & 47.0 & \multirow{2}{*}{0.13} \\
\hline Range & $19-81$ & $21-80$ & \\
\hline \multicolumn{4}{|l|}{ Gender } \\
\hline Male & $12(11.5)$ & $12(29.3)$ & \multirow{2}{*}{0.01} \\
\hline Female & $92(88.5)$ & $29(70.7)$ & \\
\hline \multicolumn{4}{|l|}{ Drugs* } \\
\hline DMARDs & $73(70.2)$ & - & NA \\
\hline Corticosteroid & $71(68.3)$ & - & NA \\
\hline NSAID & $35(33.7)$ & - & NA \\
\hline Anti-acid & $16(15.4)$ & - & NA \\
\hline Analgesic & $11(10.6)$ & - & NA \\
\hline Psychotropic & $10(9.6)$ & - & NA \\
\hline Anti-hypertensive & $23(22.1)$ & - & NA \\
\hline Anti-histaminic & $2(1.9)$ & - & NA \\
\hline Antiplatelet & $5(4.8)$ & - & NA \\
\hline Antibiotic & $2(1.9)$ & - & NA \\
\hline Beta-blocker & $3(2.9)$ & - & NA \\
\hline Diuretic & $11(10.6)$ & - & NA \\
\hline \multicolumn{4}{|l|}{ Daily habits** } \\
\hline Cigarrete & $18(17.5)$ & $7(19.4)$ & 0.80 \\
\hline Alcohol & $10(10.0)$ & $2(2.8)$ & 1.00 \\
\hline Coffee & $69(69.0)$ & $12(33.3)$ & $<0.01$ \\
\hline Marijuana & 0 & $1(2.8)$ & 0.26 \\
\hline \multicolumn{4}{|c|}{ Amount of liquid ingested per day** } \\
\hline$<1 / 2 \mathrm{~L}$ & $15(15.0)$ & 0 & 0.04 \\
\hline$>1 / 2$ and $<1 \mathrm{~L}$ & $38(38.0)$ & $7(28.0)$ & 0.48 \\
\hline$>1$ and $<2 \mathrm{~L}$ & $30(30.0)$ & $14(56.0)$ & 0.20 \\
\hline$>2 \mathrm{~L}$ & $16(16.0)$ & $3(12.0)$ & 0.76 \\
\hline
\end{tabular}

$\mathrm{NA}=$ not applicable; DMARDs = disease-modifying antirheumatic drugs; ${ }^{*}$ Individuals could take more than one type of drug. ${ }^{* *}$ Information not available for every subject in study.

Table 2. Symptoms related to salivary function of the 145 studied subjects.

\begin{tabular}{|c|c|c|c|}
\hline \multirow{2}{*}{ Characteristics } & Rheumatoid arthritis & Control group & \multirow{2}{*}{ p-value } \\
\hline & $\mathrm{n}=104(\%)$ & $\mathrm{n}=41(\%)$ & \\
\hline \multicolumn{4}{|l|}{ Answers to questionnaire* } \\
\hline Have you had a daily feeling of dry mouth for more than three months? & $57(55.3)$ & 0 & $<0.01$ \\
\hline Have you had recurrently or persistent swollen salivary glands as an adult? & $20(19.4)$ & 0 & $<0.01$ \\
\hline Do you frequently drink liquids to aid swallowing dry food? & $33(32.0)$ & 0 & $<0.01$ \\
\hline \multicolumn{4}{|l|}{ Xerostomia** } \\
\hline Do not present xerostomia & $33(33.3)$ & $39(97.5)$ & $<0.01$ \\
\hline Xerostomia occasionally & $9(9.1)$ & $1(2.5)$ & 0.28 \\
\hline Xerostomia $\leq 6$ months & $11(12.2)$ & 0 & 0.03 \\
\hline Xerostomia $>6$ months and $\leq 1$ year & $10(9.8)$ & 0 & 0.06 \\
\hline Xerostomia $>1$ and $\leq 2$ years & $10(9.8)$ & 0 & 0.06 \\
\hline Xerostomia $>2$ years & $23(22.5)$ & 0 & $<0.01$ \\
\hline
\end{tabular}

${ }^{*}$ American-European consensus group proposed criteria ${ }^{15}$; ${ }^{* *}$ Information not available for every subject in study. 
Table 3. Salivary gland characteristics of the 145 studied subjects.

\begin{tabular}{|c|c|c|c|}
\hline \multirow{2}{*}{ Salivary gland characteristics } & Rheumatoid arthritis & Control group & \multirow{2}{*}{$p$-value } \\
\hline & $\mathrm{n}=104(\%)$ & $\mathrm{n}=41(\%)$ & \\
\hline \multicolumn{4}{|c|}{ Salivary gland enlargement (on exam) } \\
\hline Parotid glands & 0 & 0 & - \\
\hline Submandibular gland & $1(0.9)$ & 0 & 1.00 \\
\hline \multicolumn{4}{|c|}{ Positive drainage from major salivary glands } \\
\hline Parotid glands & $90(86.5)$ & $41(100.0)$ & 0.01 \\
\hline Submandibular gland & $93(89.4)$ & $41(100.0)$ & 0.03 \\
\hline Minor labial glands & $93(89.4)$ & $41(100.0)$ & 0.03 \\
\hline \multicolumn{4}{|l|}{ Salivary flow rates $(\mathrm{mL} / \mathrm{min})$} \\
\hline \multicolumn{4}{|l|}{ Resting } \\
\hline Median & 0.24 & 0.40 & \multirow{2}{*}{0.04} \\
\hline Range & $0-1.20$ & $0.10-1.40$ & \\
\hline \multicolumn{4}{|l|}{ Stimulated } \\
\hline Median & 1.31 & 1.52 & \multirow{2}{*}{0.33} \\
\hline Range & $0-4.5$ & $0.68-3.80$ & \\
\hline \multicolumn{4}{|l|}{ Degree of salivary function } \\
\hline \multicolumn{4}{|l|}{ Resting SFRs } \\
\hline Hyposalivation & $20(19.2)$ & $1(2.4)$ & \multirow{3}{*}{$<0.01$} \\
\hline Intermediate & $36(34.6)$ & $7(17.1)$ & \\
\hline Normal & $48(46.2)$ & $33(80.5)$ & \\
\hline \multicolumn{4}{|l|}{ Stimulated SFRs } \\
\hline Hyposalivation & $25(24.0)$ & $2(4.9)$ & \multirow{3}{*}{0.03} \\
\hline Intermediate & $7(6.7)$ & $3(7.3)$ & \\
\hline Normal & $72(69.2)$ & $36(87.8)$ & \\
\hline
\end{tabular}

$\mathrm{SFR}=$ salivary flow rates.

RA subjects $(0.12 \mathrm{~mL} / \mathrm{min}$; range $0-1.08 \mathrm{~mL} / \mathrm{min})$ was lower than controls, but no differences were observed in the stimulated SFR between these subjects with no drainage and controls.

When theSFR of the subjects with RA who reported xerostomia were compared to the ones not presenting xerostomia, the median resting SFR were $0.20 \mathrm{~mL} / \mathrm{min}$ and $0.42 \mathrm{~mL} / \mathrm{min}$, respectively ( $\mathrm{p}<0.01$ ); and the median stimulated SFR were $1.1 \mathrm{~mL} / \mathrm{min}$ for those who reported xerostomia and $1.6 \mathrm{~mL} / \mathrm{min}$ for those not presenting any feeling of dry mouth $(\mathrm{p}<0.01)$ (Figure 1$)$.

Xerogenic drugs may be responsible for reduced SFR, and there were $45.2 \%$ of the RA subjects using xerogenic medications. When these RA subjects using xerogenic medications were analyzed, the median resting SFR was $0.24 \mathrm{~mL} / \mathrm{min}$ (range $0-1.08 \mathrm{~mL} / \mathrm{min}$ ), and they presented lower median SFR than controls $(p=0.005)$. The median stimulated SFR of RA subjects taking xerogenic medications was $1.22 \mathrm{~mL} / \mathrm{min}$ (range $0-2.76 \mathrm{~mL} / \mathrm{min}$ ), and there was no significant difference between this group and controls $(p=0.13)$ (Figure 2). There were no significant differences, when the resting and stimulated SFR were compared between RA subjects using or not xerogenic drugs.

The resting SFR of RA subjects using xerogenic medication were lower than controls. But, when the 47 subjects using xerogenic medications were eliminated from the analysis, no differences between groups were found in the median resting (RA group: median $0.36 \mathrm{~mL} / \mathrm{min} ; \mathrm{p}=0.83$ ) or stimulated SFR (RA group: median $1.36 \mathrm{~mL} / \mathrm{min}$; $\mathrm{p}=0.30$ ). However, the number of subjects with hyposalivation was still higher in the RA group (Table 4). Xerostomia was observed in $53.8 \%$ of subjects not using xerogenic medications, and $15.4 \%$ of them did not present saliva drainage from at least one of the major glands. The amount of ingested liquids were not different than controls. 
A

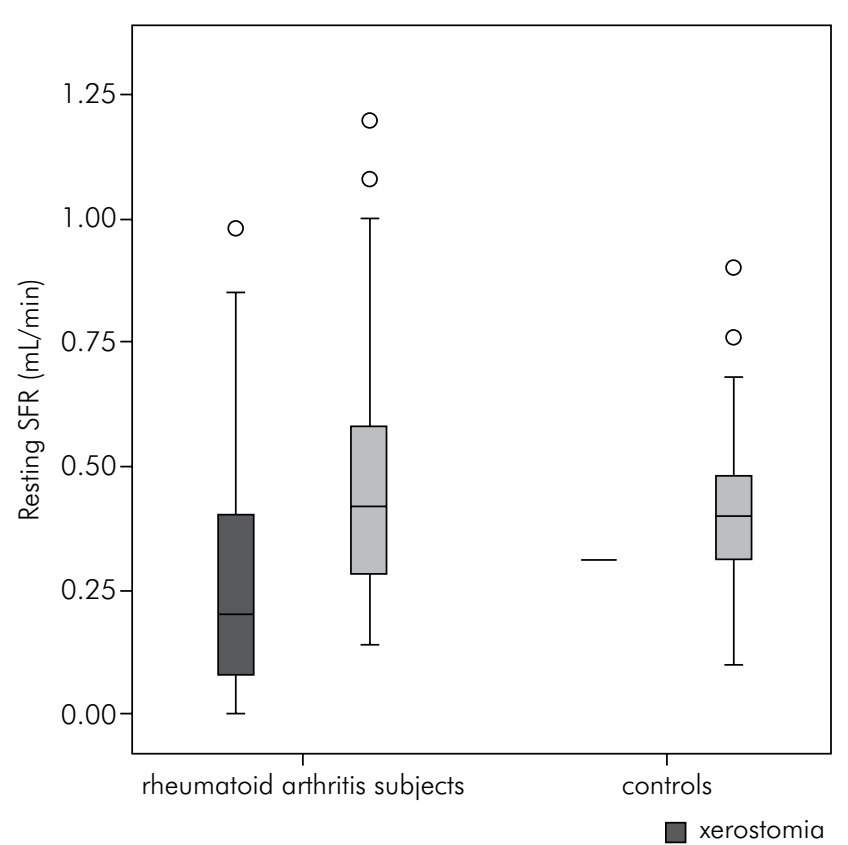

B

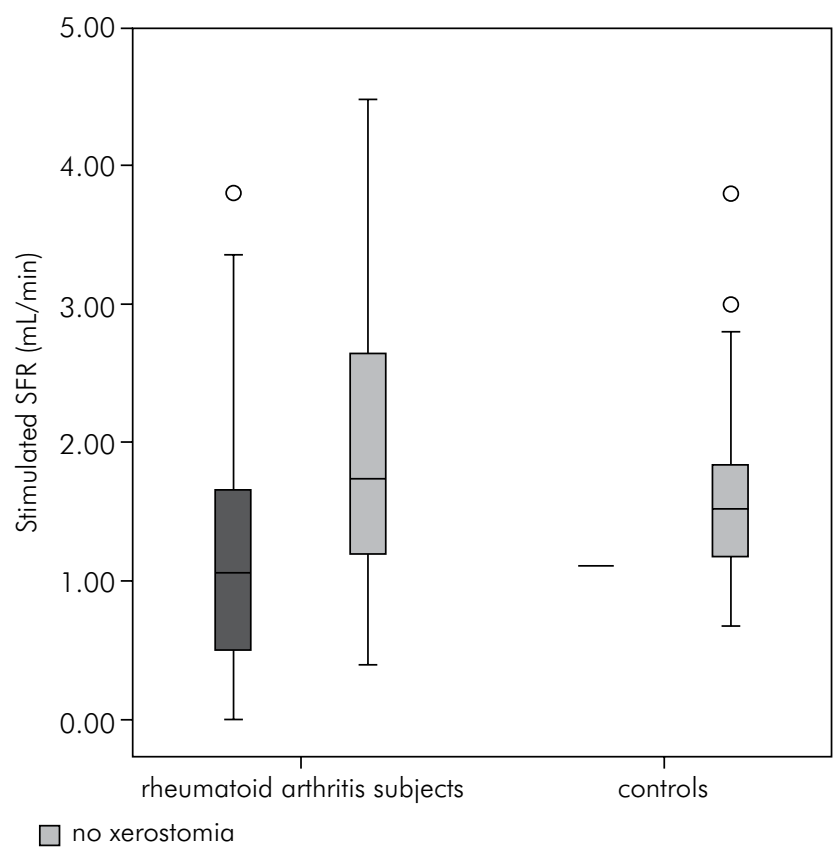

SFR: salivary flow rates.

Figure 1. Box-plot graph with the resting (A) and stimulated (B) salivary flow rates of the 145 rheumatoid arthritis subjects separated by the feeling of dry mouth.

A

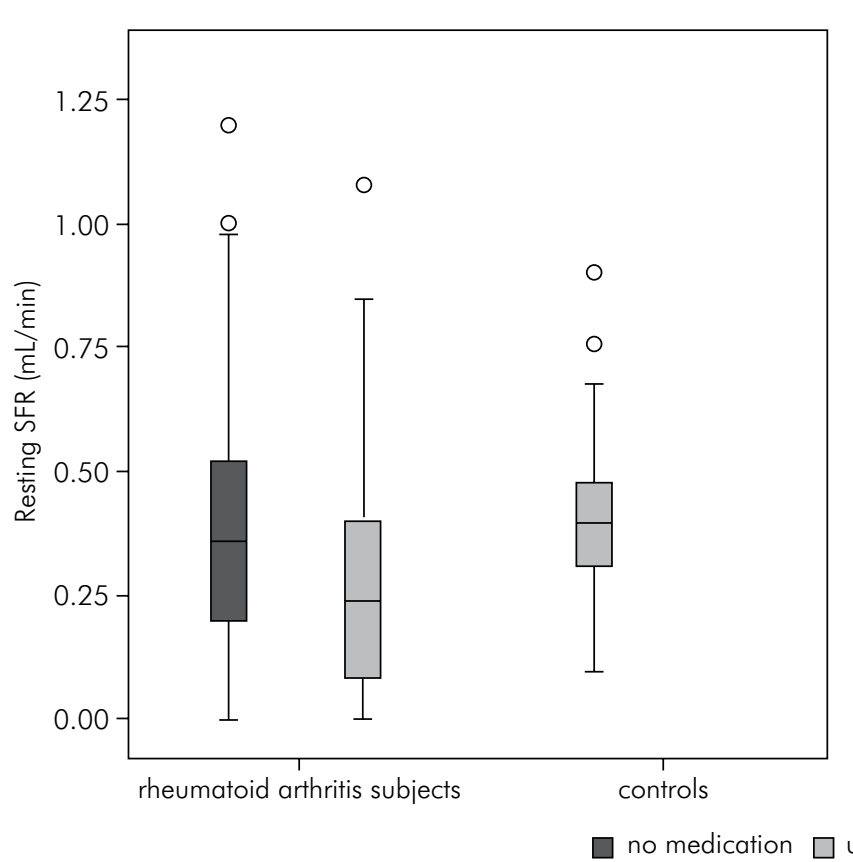

B

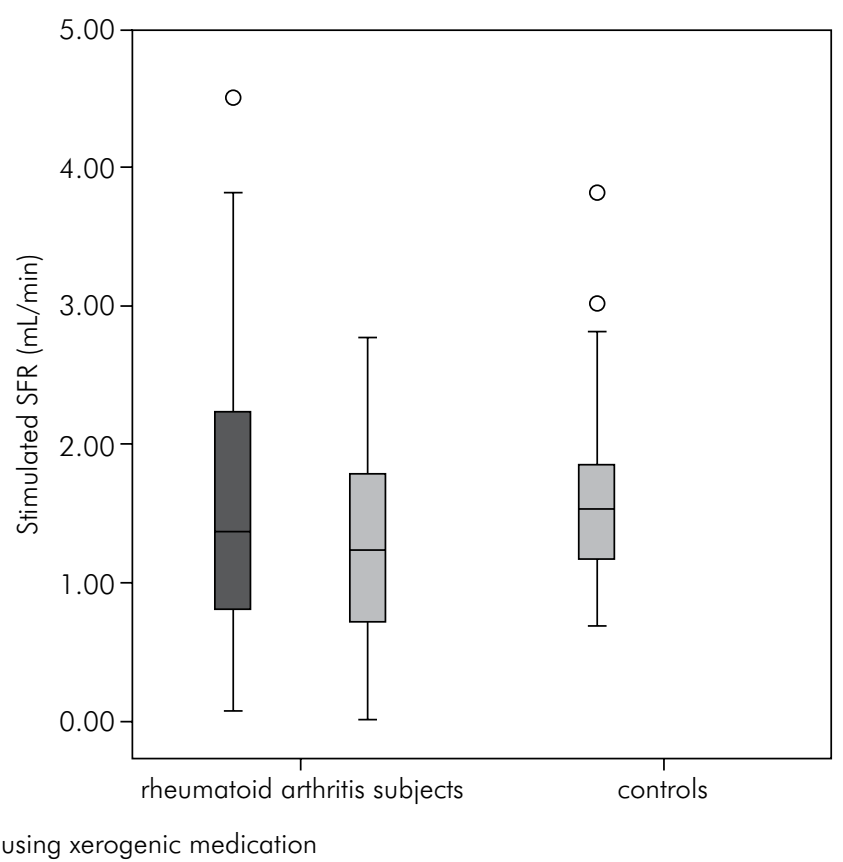

SFR: salivary flow rates.

Figure 2. Box plot graph of the resting (A) and stimulated (B) salivary flow rates of the 145 studied subjects separated by group and the use of xerogenic drugs. 
Sixty five percent of the RA subjects presenting hyposalivation (defined by resting SFR) were using xerogenic drugs. No difference was observed in the number of subjects presenting hyposalivation when the two subgroups of RA subjects (using or not xerogenic drugs) were compared. The number of subjects with hyposalivation (defined by resting SFR) was higher in the RA group than in the control group, even subjects using xerogenic medications were eliminated from the analysis (Table 4).

Regarding the protection factor given from corticosteroids or DMARDs on the SFR, no statistical significant differences were found in the median resting and stimulated SFR when subjects taking or not these drugs were compared with each other and with controls.

As there might be gender variations of the SFR, an evaluation of separate male and female genders were performed in subjects not using xerogenic medications, and no differences were observed in the median resting and stimulated SFR between groups.

\section{Discussion}

In the present study subjects with RA presented reduced resting SFR when compared to healthy controls. However, when a subset of RA subjects not using xerogenic medications was evaluated, there were no differences between the SFR of RA subjects and controls. These results suggest that medication is the cause of reduced salivary function of these subjects, not the disease itself.

Published studies show controversial results about the salivary function of the RA population ${ }^{2,6,6,9,11}$, mainly because of differences in methodology. Most of these studies evaluate RA subjects with secondary autoimmune diseases, like Sjögren's syndrome. In the present study, subjects with Sjögren's syndrome and other immunomediated/colagenous disease were eliminated from the analysis, so there would be no confounding factors.

Secondary Sjögren's syndrome is commonly related to other autoimmune diseases and should be often

Table 4. Salivary flow rates characteristics of the of the 145 studied subjects subjects according to the use of xerogenic medication.

\begin{tabular}{|c|c|c|c|c|c|}
\hline \multirow[t]{2}{*}{ Salivary gland characteristics } & $\begin{array}{l}\text { RA not using xerogenic } \\
\text { medications }\end{array}$ & $\begin{array}{l}\text { RA using xerogenic } \\
\text { medications }\end{array}$ & Control group & \multirow[t]{2}{*}{ pl-value } & \multirow[t]{2}{*}{ p2 value } \\
\hline & $\mathrm{n}=57(\%)$ & $\mathrm{n}=47(\%)$ & $\mathrm{n}=41(\%)$ & & \\
\hline \multicolumn{6}{|l|}{ Salivary Flow Rates (mL/min) } \\
\hline \multicolumn{6}{|l|}{ Resting } \\
\hline Median & 0.36 & 0.24 & 0.40 & \multirow{2}{*}{0.83} & \multirow{2}{*}{$<0.001$} \\
\hline Range & $0-1.20$ & $0-1.08$ & $0.10-1.40$ & & \\
\hline \multicolumn{6}{|l|}{ Stimulated } \\
\hline Median & 1.36 & 1.22 & 1.52 & \multirow{2}{*}{0.30} & \multirow{2}{*}{0.03} \\
\hline Range & $0-4.5$ & $0-2.76$ & $0.68-3.80$ & & \\
\hline \multicolumn{6}{|l|}{ Degree of salivary function } \\
\hline \multicolumn{6}{|l|}{ Resting SFRs } \\
\hline Hyposalivation & 7 (12.3) & $13(27.7)$ & $1(2.4)$ & \multirow{3}{*}{0.02} & \multirow{3}{*}{$<0.001$} \\
\hline Intermediate & $19(33.3)$ & $17(36.2)$ & $7(17.1)$ & & \\
\hline Normal & $31(54.4)$ & $17(36.2)$ & $33(80.5)$ & & \\
\hline \multicolumn{6}{|l|}{ Stimulated SFRs } \\
\hline Hyposalivation & $12(21.1)$ & $13(27.7)$ & $2(4.9)$ & \multirow{3}{*}{0.07} & \multirow{3}{*}{0.01} \\
\hline Intermediate & $4(7.0)$ & $3(6.4)$ & $3(7.3)$ & & \\
\hline Normal & 41 (71.9) & $31(66.0)$ & $36(87.8)$ & & \\
\hline
\end{tabular}

SFR: salivary flow rates; RA: Rheumatoid arthritis; $\mathrm{p} 1$ : differences between RA not using xerogenic medications and controls; p2: differences between RA using xerogenic medications and controls; $p 1$ and $p 2$ were adjusted for two comparisons $(p<0.025)$. 
investigated in subjects with RA ${ }^{15}$. This syndrome is a major cause for hyposalivation and it has represented a concern when evaluating the salivary function from subjects with RA. Secondary Sjögren's syndrome has been reported as affecting $22.2 \%$ of the subjects with $\mathrm{RA}^{24}$. A similar frequency has been observed in this population, as there were $19.6 \%$ subjects with Sjögren's syndrome secondary to other autoimmune diseases, before study criteria was applied (data not shown). But Sjögren's syndrome secondary to RA was observed in $8.9 \%$ of cases. It is possible that secondary Sjögren's syndrome would still develop in some of these subjects on later stages of the disease. Longitudinal studies are needed to investigate the early onset of secondary Sjögren's syndrome in the population of RA patients.

There were no differences in the median SFR of groups, when subjects using xerogenic medications were isolated from the analysis. It has been suggested that resting SFR may be more influenced from disease than the stimulated $\mathrm{SFR}^{9,25,26}$ and medication mainly affect the stimulated SFR ${ }^{27}$. Data on Figure 2 suggest that xerogenic drugs have influenced both resting and stimulated SFR, although differences are not statistically significant for stimulated SFR.

Interestingly, the frequency of hyposalivation (defined by resting SFR) was higher in subjects with RA, than among controls, even when subjects using xerogenic drugs were eliminated from the analysis. There may be a variety of reasons for finding a higher number of subjects with hyposalivation but not finding a reduction in the median SFR of these subjects. The wide variation in the SFR and also the extremes and outlier cases may be one of the reasons. Other reasons for this finding need to be explored.

Xerostomia may be a symptom neglected from individuals and health care professionals ${ }^{28}$. The complaint of dry mouth in RA subjects has varied from $21 \%$ to $41.3 \%$, according to different studies ${ }^{6,11}$, but was higher in the present study $(66.7 \%)^{11,19}$. Maybe, medications, neurologic conditions, alterations in sialochemistry or other unknown reason may be responsible for this symptom. Interestingly, xerostomia was very frequent $(53.8 \%)$ even in the RA subjects not using xerogenic medication.
Reduced SFR is the most common cause of xerostomia ${ }^{19}$. In fact, RA subjects who presented xerostomia showed lower median SFR than those who did not have the symptom of dry mouth. This aspect should not be generalized for every individual, because some subjects who did not present xerostomia had low SFR and some others presenting xerostomia had normal SFR. This fact is in agreement with other authors ${ }^{8}$, and may be verified in the present study by observing extremes and outliers in Figure 1.

Salivary gland enlargement may be one of the signs of Sjögren's syndrome, but it may also be a sign of infection or other metabolic disease. The submandibular gland enlargement that was reported by of one RA subject might have probably represented an infection, as it resolved with antibiotics.

Clinical drainage of major salivary glands is a non-invasive easy and relatively quick procedure, which represents actual status of isolated glands. It does not expose patients to radiation, like the scintigraphy. In the studied population, more than $10 \%$ of RA subjects were lacking saliva drainage from at least one of the major salivary glands. Future studies need to explore the importance of the clinical saliva drainage from major glands for the disease staging and its correlation to Sjögren's syndrome.

Subjects with hyposalivation are usually instructed to avoid the use of some substances like tobacco, cannabis, alcohol and caffeine, as they might interfere in salivary function ${ }^{29}$. In the studied population, the only difference in habits between the two groups was the consumption of coffee, but no differences were found in the SFR of subjects who did or not have the habit of consuming coffee (data not shown).

Gender variations of the SFR have been reported ${ }^{19}$, and it might have represented a flaw in this study, as there was a significant difference in gender between groups. Thus, we have evaluated the SFR of separate genders between groups and found no significant differences in SFR. This finding eliminates the problem of gender variation.

Future longitudinal studies should be developed, in order to determine if early detection of reduced SFR in RA subjects may predict secondary Sjögren's syndrome. Health care professionals should be able to diagnose and manage early salivary dysfunction appropriately. 


\section{Conclusion}

In the studied population of rheumatoid arthritis individuals, the salivary flow rates of the subjects not using xerogenic medications were not different from the healthy controls. However, cases of hyposalivation and xerostomia were more frequent in the rheumatoid arthritis group. Xerogenic medications may be partially responsible for the reduction of salivary function, but other factors that lead to the decrease of salivary flow rates and the increase of xerostomia need to be further investigated, in populations with rheumatoid arthritis.

\section{References}

1. Aletaha D, Neogi T, Silman AJ, Funovits J, Felson

DT, Bingham CO, 3rd et al. 2010 Rheumatoid

arthritis classification criteria: an American College

of Rheumatology/European League Against

Rheumatism collaborative initiative. Arthritis Rheum.

2010;62(9):2569-81. doi:10.1002/art.27584

2. Moen K, Bertelsen LT, Hellem S, Jonsson R, Brun JG. Salivary gland and temporomandibular joint involvement in rheumatoid arthritis: relation to disease activity. Oral Dis. 2005;11(1):27-34. doi:10.1111/j.1601-0825.2004.01054.x

3. Garib BT, Qaradaxi SS. Temporomandibular joint problems and periodontal condition in rheumatoid arthritis patients in relation to their rheumatologic status. J Oral Maxillofac Surg. 2011;69(12):2971-8. doi:10.1016/j.joms.2011.02.131

4. Pedrazas $\mathrm{CH}$, Azevedo MN, Torres SR. Oral events related to low-dose methotrexate in rheumatoid arthritis patients. Braz Oral Res. 2010;24(3):368-73. doi:10.1590/S1806-83242010000300018

5. Guobis Z, Baseviciene N, Paipaliene P, Niedzelskiene I, Januseviciüte G. Aspects of xerostomia prevalence and treatment among rheumatic inpatients. Medicina (Kaunas). 2008;44(12):960-8.

6. Geterud A, Bake B, Bjelle A, Jonsson R, Sandberg N, Ejnell H. Swallowing problems in rheumatoid arthritis. Acta Otolaryngol. 1991;111(6):1153-61. doi:10.3109/00016489109100771

7. Helenius LM, Hietanen JH, Helenius I, Kautiainen H, Piirainen H, Paimela L et al. Focal sialadenitis in patients with ankylosing spondylitis and spondyloarthropathy: a comparison with patients with rheumatoid arthritis or mixed connective tissue disease. Ann Rheum Dis. 2001;60(8):744-9. doi:10.1136/ard.60.8.744

8. Nederfors T, Holmström G, Paulsson G, Sahlberg D. The relation between xerostomia and hyposalivation in subjects with rheumatoid arthritis or fibromyalgia. Swed Dent J. 2002;26(1):1-7.

\section{Acknowledgements}

Authors acknowledge Dr. Daniela Amorim Marco Peres, Dr. Elaine Lima Amorim, Dr. Erika Santana de Amorim, Dr. Fabiana da Cunha Corrêa, Dr. Luciana Uemoto, Dr. Marcelle Teixeira Paulo, Dr. Michelle C. Ferreira, Dr. Rafael de Lima Pedro, Dr. Renata Mendes de Sousa, and Dr. Silviane Franco Ruela, who during their period as dental students at the Universidade Federal do Rio de Janeiro, helped with data collection for the study.

9. Nagler RM, Nagler A. Sialometrical and sialochemical analysis of patients with chronic graft-versus-host disease: a prolonged study. Cancer Invest. 2003;21(1):34-40. doi:10.1081/CNV-120016401

10. Helenius M, Leirisalo-Repo M. [Oral complications in patients with rheumatoid arthritis]. Duodecim. 2005;121(21):2333-7. Finnish.

11. Oliveira HF, de Souza TR, Carvalho CN, Duarte A, Carvalho AT, Leão JC et al. Serologic profile and clinical markers of Sjögren syndrome in patients with rheumatoid arthritis. Oral Surg Oral Med Oral Pathol Oral Radiol. 2015;119(6):628-35. doi: 0.1016/j.oooo.2015.02.479

12. Cojocaru M, Cojocaru IM, Silosi I, Vrabie CD, Tanasescu R. Extra-articular Manifestations in Rheumatoid Arthritis. Maedica (Buchar). 2010;5(4):286-91.

13. Torres SR, Paulo MT, Ruela SF, Corrêa FC, Oliveira TM, Uemoto L et al. [Quantitative analysis of salivary flow rates of patients with rheumatoid arthritis]. Braz Oral Res. 2004;18 Suppl:145. Portuguese.

14. Janin-Mercier A, Sauvezie B, Ristori JM, Betail G, Veyre A, Rampon S. Histological and immunological study in patients with rheumatoid arthritis showing isolated abnormalities of salivary scintigraphy. J Clin Immunol. 1982;2(4):282-8. doi:10.1007/BF00915068

15. Vitali C, Bombardieri S, Jonsson R, Moutsopoulos HM, Alexander EL, Carsons SE et al. Classification criteria for Sjögren's syndrome: a revised version of the European criteria proposed by the American-European Consensus Group. Ann Rheum Dis. 2002;61(6):554-8. doi:10.1136/ard.61.6.554

16. Nonzee V, Manopatanakul S, Khovidhunkit SO. Xerostomia, hyposalivation and oral microbiota in patients using antihypertensive medications. J Med Assoc Thai. 2012;95(1):96-104. 
17. Samnieng P, Ueno M, Shinada K, Zaitsu T, Wright FA, Kawaguchi Y. Association of hyposalivation with oral function, nutrition and oral health in community-dwelling elderly Thai. Community Dent Health. 2012;29(1):117-23. doi:10.1922/CDH_2690Ueno07

18. Vissink A, Mitchell JB, Baum BJ, Limesand KH, Jensen SB, Fox PC, et al. Clinical management of salivary gland hypofunction and xerostomia in head-and-neck cancer patients: successes and barriers. Int J Radiat Oncol Biol Phys. 2010;78(4):983-91. doi:10.1016/j.ijrobp.2010.06.052

19. Torres SR, Peixoto CB, Caldas DM, Silva EB, Akiti T, Nucci $M$ et al. Relationship between salivary flow rates and Candida counts in subjects with xerostomia. Oral Surg Oral Med Oral Pathol Oral Radiol Endod. 2002;93(2):149-54. doi:10.1067/moe.2002.119738

20. Dyasanoor S, Saddu SC. Association of xerostomia and assessment of salivary flow using modified schirmer test among smokers and healthy individuals: a preliminutesary study. J Clin Diagn Res. 2014;8(1):211-3. doi:10.7860/JCDR/2014/6650.3846

21. Arnett FC, Edworthy SM, Bloch DA, McShane DJ, Fries JF, Cooper NS et al. The American Rheumatism Association 1987 revised criteria for the classification of rheumatoid arthritis. Arthritis Rheum. 1988;31(3):315-24. doi:10.1002/art.1780310302

22. Zelman D. Arthritis: disease-modifying medications. Atlanta: WebMD; 2014[cited 2015 Oct 27]. Available from: http://www.webmd.com/rheumatoid-arthritis/ modifying-medications
23. Borges BC, Fulco GM, Souza AJ, Lima KC. Xerostomia and hyposalivation: a preliminary report of their prevalence and associated factors in Brazilian elderly diabetic patients. Oral Health Prev Dent. 2010;8(2):153-8.

24. Kosrirukvongs P, Ngowyutagon P, Pusuwan P, Koolvisoot A, Nilganuwong S. Prevalence of dry eye syndrome and Sjogren's syndrome in patients with rheumatoid arthritis. J Med Assoc Thai. 2012;95 Suppl 4:S61-9.

25. Leal SC, Bittar J, Portugal A, Falcão DP, Faber J, Zanotta P. Medication in elderly people: its influence on salivary pattern, signs and symptoms of dry mouth. Gerodontology. 2010;27(2):129-33. doi:10.1111/j.1741-2358.2009.00293.x

26. Smidt D, Torpet LA, Nauntofte B, Heegaard KM, Pedersen AM. Associations between labial and whole salivary flow rates, systemic diseases and medications in a sample of older people. Community Dent Oral Epidemiol. 2010;38(5):422-35. doi:10.1111/j.1600-0528.2010.00554.x

27. Johanson $\mathrm{CN}$, Österberg T, Lernfelt B, Ekström J, Birkhed D. Salivary secretion and drug treatment in four 70-year-old Swedish cohorts during a period of 30 years. Gerodontology. 2015;32(3):202-10. doi:10.1111/ger.12089

28. Wilczynska-Borawska M, Baginska J, Borawski J. Is xerostomia a risk factor for cardiovascular morbidity and mortality in maintenance hemodialysis patients? Med Hypotheses. 2012;79(4):544-8. doi:10.1016/j.mehy.2012.07.016

29. Veitz-Keenan A, Spivakovsky S. Cannabis use and oral diseases. Evid Based Dent. 2011;12(2):38. doi:10.1038/sj.ebd.6400786 